\title{
New HIV peptide-based immunoassay resolves vaccine-induced seropositivity in HIV vaccine (Phase III) trial participants
}

\author{
O Penezina ${ }^{1 *}$, D Clapham¹, J Collins ${ }^{1}$, V Kovalenko ${ }^{1}$, N Krueger $^{1}$, IR Rodriguez-Chavez², MP Busch ${ }^{3}$, AE Levin ${ }^{1}$
}

From AIDS Vaccine 2012

Boston, MA, USA. 9-12 September 2012

\section{Background}

HIV Vaccine trials bring the significant risk of vaccineinduced HIV seropositivity(VISP) resulting in negative personal consequences for vaccinees. The overall rate of VISP in licensed EIA tests is reported as $41.7 \%$ (JAMA 2010;304:275-283). We have developed and modified the peptide-based HIV Selectest immunoassay(J.Virol 2006;80:2092-2099), which discriminates VISP from true HIV infection, in a format suitable for routine laboratory use, and have evaluated its performance on samples from three Phase III HIV vaccine trials.

\section{Methods}

The HIV Selectest incorporated five synthetic peptides in a single well microplate ELISA. Serum panels evaluated comprised well-characterized HIV-positive sera from clades A,B and C, worldwide panels comprising all major clades, blood donor controls, and sera from vaccine and placebo recipients in RV144, Vax003 and Vax004 trials.

\section{Results}

360 serum samples from the RV144 vaccine trial, including 170 samples from vaccinated subjects at the peak immune response, 120 pre-immune samples, and 70 subjects from the placebo group were tested on the HIV Selectest. One (1) subject $(0.6 \%)$ among the vaccine recipient group yielded false-positive results, while 3 placebo recipients $(4.3 \%)$ and 1 pre-immune serum sample $(0.8 \%)$ were also false positive in the HIV Selectest. All false-positive samples demonstrated broad non-specific cross-reactivity that was not restricted to a particular HIV-specific peptide.
Similar results were obtained with samples from the VAX003 and VAX004 vaccine trials. One subject out of $87(1.2 \%)$ tested after the final vaccination $\left(7^{\text {th }}\right.$ visit) at the peak of the immune response was detected as false positive. Two additional samples out of 96(2.1\%) taken after the $4^{\text {th }}$ visit were likewise detected as false-positive, bringing the average false-positive rate for both groups to $1.6 \%$.

Blood donors yielded a statistically equivalent false-positive rate of $1.2 \%$. Detection sensitivity for HIV positive samples was $96 \%$ among 648 serum samples representing different clades.

\section{Conclusion}

The HIV Selectest ELISA has demonstrated significantly better discrimination of VISP than currently licensed HIV serologic assays.

Author details

${ }^{1}$ Immunetics, Boston, MA, USA. ${ }^{2} \mathrm{NIH} / \mathrm{NIDCR}$, Bethesda, MD, USA. ${ }^{3}$ Blood Systems Research Institute, San Francisco, CA, USA.

Published: 13 September 2012

\section{doi:10.1186/1742-4690-9-S2-P120}

Cite this article as: Penezina et al:: New HIV peptide-based

immunoassay resolves vaccine-induced seropositivity in HIV vaccine (Phase III) trial participants. Retrovirology 2012 9(Suppl 2):P120.

Immunetics, Boston, MA, USA

Full list of author information is available at the end of the article

(c) 2012 Penezina et al; licensee BioMed Central Ltd. This is an Open Access article distributed under the terms of the Creative 